\title{
Enunciação e trabalho: a integração do homem à sua cultura profissional
}

\author{
Enunciation and work: the integration of man to his professional culture
}

Carmem Luci da Costa Silva
Lia Emília Cremonese
Simone de Lima Silveira Barros

Universidade Federal do Rio Grande do Sul - Porto Alegre - Rio Grande do Sul - Brasil

\begin{abstract}
Resumo: O objetivo deste texto é entender como um autor da área de ciências da saúde enuncia a sua posição de locutor para constituir o outro em um artigo de opinião. Para tanto, alicerça-se a investigação na noção de linguagem de Émile Benveniste e busca-se apoio na perspectiva ergológica de Yves Schwartz. Inicialmente, apresenta-se uma concepção cultural de homem atrelada a uma noção simbólica de linguagem; em seguida, desloca-se essa teorização, pensando as áreas de conhecimento como fatos culturais que imprimem valores na língua e deixam marcas nos discursos dos campos de saber; por fim, analisa-se um artigo de opinião da área da saúde, relacionando as duas primeiras partes.
\end{abstract}

Palavras-chave: Enunciação; Ergologia; Artigo de opinião

\begin{abstract}
The purpose of this text is to understand how an author of the health sciences enunciates his position of speaker for the constitution of the other person in an opinion article. For this reflection, we use as a basis Émile Benveniste's notion of the language and we seek support from Yves Schwartz's perspective of ergology. First, we present a cultural conception of "man" related to the notion of symbolic language. Then, we displace this theory, considering the knowledge areas as cultural facts that imprint values in the language and leave marks in discourse of the fields of knowledge. To conclude, we analize an opinion article from de health sciences for linking the first and the second part of this article.
\end{abstract}

Keywords: Enunciation; Ergology; Opinion article

\section{Palavras iniciais}

A esfera acadêmica exige produção de conhecimento por meio da elaboração de gêneros distintos (resumos, resenhas, monografias, ensaios, artigos etc.) para as disciplinas cursadas pelo aluno. Se esse aluno for graduando e estiver envolvido na Iniciação Científica, é preciso que divulgue os resultados de sua pesquisa e, se pós-graduando, a exigência de divulgação de seu fazer científico aumenta: é necessário que publique artigos regularmente, e que elabore dissertação (mestrando) ou tese (doutorando). Nessa "cultura acadêmica de produtividade intelectual", o texto em Língua Portuguesa ocupa um lugar central e, consequentemente, as disciplinas que tratam de leitura e de produção de textos nas universidades.
O embrião da reflexão apresentada neste artigo encontra-se nas situações de sala de aula com alunos de pós-graduação stricto sensu de diferentes campos do saber (ciências humanas, ciências exatas, ciências da saúde e da natureza), do projeto Língua Portuguesa - Leitura e Produção de Textos Científicos, que promove atividades de leitura e produção de textos no âmbito do Programa de Apoio à Graduação da Universidade Federal do Rio Grande do Sul.

Nas situações de sala de aula, algumas formulações "na minha área se escreve de tal modo, não de outro"; "na minha área não produzimos tal gênero" e assim por diante - não somente geraram inquietações nos professores para lidar com essa situação de ensino-aprendizagem como também encaminharam a equipe do Projeto Língua Portuguesa, no âmbito desse programa, a uma tomada 
de atitude de ordem metodológica: agrupar os alunos conforme seus campos de saber. Dessa situação de ensinoaprendizagem com textos em Língua Portuguesa com alunos de diferentes Programas de Pós-Graduação, ficou, como uma "sobra", a necessária reflexão que tomasse como escopo central a relação entre indivíduo e área de conhecimento, atestada nos dizeres dos alunos como um "testemunho" de suas vivências na linguagem em relação com os seus campos de conhecimento.

Considera-se que a possibilidade de o aluno fundarse nas atividades de trabalho de sua área de saber reside na faculdade humana de simbolizar as atividades de linguagem nas práticas sociais. Assim, a consideração da língua em emprego, com a abordagem de seus modos de realização (falar, escutar, ler e escrever) nas situações de ensino-aprendizagem em Língua Portuguesa, encaminha a realização de um trabalho docente que priorize a leitura de textos com temáticas relacionadas à profissão-alvo do aluno para que este se integre e se singularize nos valores dessa profissão que antecedem a sua entrada, de fato, nela.

Por isso, com base na concepção de Émile Benveniste acerca da linguagem, busca-se neste texto responder à seguinte questão: "como um autor da área de ciências da saúde enuncia a sua posição de locutor para implantar o outro diante de si em um artigo de opinião?".

Como a faculdade simbolizante está na base das funções conceituais e, por conseguinte, da significação, adota-se a posição de que o aluno se constitui subjetivamente como pertencendo a um determinado campo em uma relação enunciativa com outro por meio da leitura de textos de sua área de saber. Se há valores sociais que se imprimem nos discursos de profissionais de cada campo de saber, torna-se interessante analisar o modo como cada profissional, ao converter a língua em discurso, interpreta o seu campo de atuação e constitui o outro nessa relação de interpretância. Essa relação parece situar o locutor entre o que é de ordem geral (social) da profissão com o que é de ordem particular (individual) de sua experiência nas atividades de trabalho. Essa constatação permite o profícuo encontro entre a perspectiva enunciativa de estudos da linguagem de Émile Benveniste, linguista que explora a natureza social e individual da linguagem, com a perspectiva ergológica sobre trabalho de Yves Schwartz, filósofo que investiga a relação entre o geral (as normas antecedentes presentes nas atividades de trabalho e nas atividades linguageiras) e a renormatização atualizada pelos homens que vivem imersos nessas atividades.

$\mathrm{O}$ artigo estrutura-se em três seções: na primeira, apresenta-se uma concepção cultural de homem atrelada a uma noção simbólica de linguagem; na segunda, deslocase essa teorização linguístico-cultural para pensar as diferentes áreas de conhecimento como fatos culturais que imprimem valores na língua e, por conseguinte, deixam vestígios nos discursos de distintos campos de saber e, na terceira, propõe-se a análise de um artigo de opinião do campo da saúde para articular as duas primeiras partes.

\section{A experiência humana na linguagem: do homem na cultura-língua-discurso}

A linguagem é um fato humano: é, no homem, o ponto de interação da vida mental e da vida cultural. É na interdependência desse trinômio língua-cultura-homem que se enlaça o sistema cultural com o sistema da língua, pois, como afirma Benveniste (1989, p.22): "tudo que é do domínio da cultura deriva no fundo de valores, de sistema de valores. Da articulação entre valores. Muito bem! Esses valores são os que se imprimem na língua". É por isso que o semanticista defende que a cultura é também um sistema que distingue o que tem e o que não tem sentido. É o símbolo que permite ao homem ter acesso à experiência de outro, e isso, é claro, por meio de uma determinada língua, particular a certa sociedade. Como o signo não tem relação natural com o que simboliza, para que um locutor tenha acesso à experiência de outro, é preciso constituir-se nos símbolos particulares à sociedade em que vive. Trata-se do fato de que

a apropriação da linguagem pelo homem é a apropriação da linguagem pelo conjunto de dados que se considera que ela traduz, a apropriação da língua por todas as conquistas intelectuais que o manejo da língua permite. É algo de fundamental: o processo dinâmico da língua, que permite inventar novos conceitos e por conseguinte refazer a língua, sobre ela mesma de algum modo. Muito bem! Tudo isso é o domínio do "sentido". (BENVENISTE, 1989, p. 21)

Como os valores culturais estão impressos na língua e como enunciar é se apropriar da língua (BENVENISTE, 1989, 1995), torna-se interessante verificar como a língua carrega esses dados de cultura e como esses dados se apresentam nas relações enunciativas constituídas entre locutor e alocutário. O ponto de vista defendido no estudo é o de que cada indivíduo se instaura no mundo do homem em um enlace simbólico como chave de integração necessária entre língua e cultura na enunciação com o outro, instância em que o tesouro linguísticocultural emerge como efeito da conversão da língua em discurso a cada nova situação de enunciação. É a instância de discurso constituindo o ato e concomitantemente fundamentando o sujeito em seu movimento singular de apreensão do sistema da língua e do sistema cultural.

Como a ergologia (SCHWARTZ, 2007) trata do homem relacionado à sua atividade de trabalho como algo de ordem social e coletiva, e, ao mesmo tempo, 
de ordem individual e singular porque vinculada à experiência humana subjetiva de cada indivíduo com o seu fazer, manifestado via discurso (o dizer), considerase que a perspectiva benvenistiana sobre linguagem é um lugar privilegiado de diálogo e encontro com o campo ergológico. Esse encontro parece circunscrever uma Linguística projetada por Benveniste no texto Tendências recentes em linguística geral (1954): "uma outra linguística poderia estabelecer-se sobre os termos deste trinômio: língua-cultura-personalidade" (BENVENISTE, 1995, p. 17).

A relação que o homem estabelece com o mundo e com o outro somente é possível pela linguagem, por meio de relações de interpretância, em que a língua figura como sistema interpretante por excelência porque comporta, em sua estrutura e em seu funcionamento, quatro aspectos: 1) a possibilidade de manifestação pela enunciação para constituir referência a uma situação dada; 2) unidades em relação; 3 ) os valores partilhados pelos membros de uma comunidade; e 4) o lugar de atualização da comunicação intersubjetiva.

Considerando a formulação produzida por Benveniste (1989, p. 99) de que "nada pode ser compreendido que não tenha sido reduzido à língua [...] É graças a este poder de transmutação da experiência em signos e de redução categorial que a língua pode tomar por objeto qualquer ordem de dados e até a sua própria natureza", tem-se como resultado que a língua, ao englobar a sociedade, instaura o que o autor chama de um "semantismo social", que permite a ela, quando colocada em atividade na enunciação, fazer emergir "a variação da referência na estabilidade da significação" (BENVENISTE, 1989, p. 100). Se há, de um lado, um valor significativo das unidades da língua, o que garante sua estabilidade de significação, há, de outro lado, a singularidade da referência, que se constitui em cada discurso enunciado. Se há algo de estável quando da conversão do signo (mundo da língua) em palavra (mundo do discurso) no momento em que cada locutor testemunha sua experiência nas atividades de trabalho, há algo de único, porque estabelece, de modo próprio, "certa" relação com o mundo ligado a seu campo de atuação.

No texto Estrutura da língua e da sociedade, ao articular homem e sociedade via língua em ação no discurso, Benveniste (1989) trata de duas grandes operações que tornam possível o discurso: a estrutura de alocução pessoal, exclusivamente inter-humana, que se apresenta na oposição entre "eu" e "tu", e a "operação de referência", representada por "ele", já que "eu" discursiviza para "tu" "sobre alguma coisa, sobre o mundo, sobre o que não é alocução" (BENVENISTE, 1989, p. 101). Essa segunda oposição "eu-tu/ele" é o que fundamenta a possiblidade de discurso e é também o que torna possível ao homem articular língua e cultura.
Levando em conta a referência atualizada em cada discurso como atravessada pela dimensão cultural impressa na língua, é relevante pensar as situações em que se realizam os atos de enunciação relacionados às atividades de trabalho com a consideração da estabilidade de significação constitutiva dos discursos dessas atividades e a variação de referência presente no modo como cada locutor simboliza, em seu ato enunciativo, a relação que estabelece com a sua atividade de trabalho, visto que regularidade e particularidade estão envolvidas na "intervenção sempre singular do sujeito no ato de linguagem/na atividade de trabalho" (TEIXEIRA; CABRAL, 2009, p. 237).

A retomada da reflexão de Benveniste, com destaque para alguns pontos de sua obra, permite argumentar que cada discurso, como produto da enunciação de um locutor, carrega, na referência atualizada do discurso nas formas de não-pessoa, uma parte vazia possível de ser preenchida no ato enunciativo de sintagmatização das palavras que, no caso deste estudo, realizar-se-á pela análise de um artigo de opinião, por meio da exploração do valor (sentido) que o leitor-analista-locutor atribui a essas formas atualizadas pelo autor-locutor no ato de escrita, com a consideração do trinômio homem-língua-cultura nos discursos sobre os distintos campos de atividade humana. Com isso, o sentido do discurso (sua ideia) emerge da exploração do sentido da palavra em emprego, conforme reflexão de Benveniste em A forma e o sentido na linguagem, em que intersubjetividade e referência estão interligadas e atravessadas pela dimensão cultural que as constituem. Como a leitura é um ato de enunciação (NAURJORKS, 2011), a constituição de sentidos na análise de textos (discursos) faz emergir, na relação intersubjetiva, a referência no discurso como ligada à interpretância de valores culturais daquela atividade de trabalho atrelados aos valores singulares que o discurso lido evoca pela sintagmatização de formas.

Se se adota que há valores culturais que se imprimem na língua, o locutor, ao se apropriar dela, carrega para seu discurso esses valores já impressos em sua língua. A questão está em considerar como esse ato individual singulariza uma língua e uma cultura que são de ordem social. É inserido nessa concepção que Benveniste considera a existência de uma natureza duplamente paradoxal na língua, ao mesmo tempo imanente ao indivíduo e transcendente à sociedade. Essa dualidade, para o autor, encontra-se em todas as propriedades da língua e, como tal, manifesta-se na sua conversão em discurso, lugar em que a língua se mostra como interpretante da sociedade. Por distinguir o que tem e o que não tem sentido, a cultura manifesta-se no domínio semântico (no mundo do discurso), mas carregando os valores do domínio semiótico (o mundo do signo). Nesse 
caso, a definição que Benveniste circunscreve para cultura fundamenta a reflexão:

Chamo cultura ao meio humano, tudo o que, do outro lado do cumprimento das funções biológicas, dá à vida e à atividade humanas forma, sentido e conteúdo. A cultura é inerente à sociedade dos homens, qualquer que seja o nível de civilização. Consiste numa multidão de noções e de prescrições, e também em interdições específicas; o que uma cultura proíbe a caracteriza ao menos tanto quanto aquilo que prescreve. (BENVENISTE, 1995, p. 31-32)

A cultura, nessa acepção, assume um estatuto de legitimação, uma vez que uma certa "regulamentação" institui um modo específico de o homem estar no mundo. De fato, o semanticista, ao tratar a cultura como um conjunto complexo de representações organizadas por um sistema de relações e de valores, considera a existência de um simbolismo que articula homem, língua e cultura em uma relação de integração necessária. É o símbolo que estabelece o elo entre os homens, a língua e a cultura.

Parafraseando Benveniste (1995, p.285), para quem "é um homem falando que encontramos no mundo, um homem falando com outro homem", pode-se afirmar que, além de um homem falando, encontra-se, no mundo, um homem escutando, escrevendo e lendo sobre suas atividades de trabalho. Ao se considerar a intersubjetividade como ligada à necessidade de o homem referir suas experiências nas diferentes modalidades de apropriação da língua - seja por meio da fala, seja por meio da escuta, seja por meio da escrita e seja por meio da leitura - contempla-se o que fundamenta a possibilidade de discurso a cada ato enunciativo: a constituição da relação intersubjetiva e o funcionamento referencial. E, uma vez que se está no domínio da língua em emprego e em ação,

vemos [...] na língua sua função mediadora entre o homem e o homem, entre o homem e o mundo, entre o espírito e as coisas, transmitindo a informação, comunicando a experiência, impondo a adesão, suscitando a resposta, implorando, constrangendo; em resumo, organizando a vida dos homens. [...] Somente o funcionamento semântico da língua permite a integração da sociedade e a adequação ao mundo [...]. (BENVENISTE, 1989, p. 229)

Dessa forma, dialogando com Silva; Juchem; Knack (2013), considera-se aqui que a concepção de experiência que sustenta este estudo é de um experimentum linguae, nos termos de Agamben (2012, p. 11), no sentido de que é "uma experiência que se sustém somente na linguagem", fazendo com que aquilo de que se tenha experiência esteja inscrito na própria língua-discurso.
A experiência humana na linguagem é o que permite ao homem historicizar-se na sua língua materna para fundar-se na dupla natureza (individual e social) dessa língua. As situações de enunciação relacionadas às atividades de trabalho são lugares privilegiados de o homem continuar sua história na linguagem por vincular o individual e o social, já que é

na prática social, comum no exercício da língua, nesta relação inter-humana que os traços comuns de seu funcionamento deverão ser descobertos, pois o homem é ainda e cada vez mais um objeto para ser descoberto, na dupla natureza que a linguagem fundamenta e instaura nele. (BENVENISTE, 1989, p. 104)

É vivendo sua experiência na linguagem com outros, em sua prática social de trabalho por meio de atos de enunciação - falado, ouvido, escrito e lido - que o homem pode descobrir-se e reinventar-se durante toda a vida. Deslocando essa reflexão para o contexto deste artigo, trata-se da busca de simbolização dos diferentes atos de enunciação do homem ligado às distintas atividades humanas, condição de cada um revelar sua experiência subjetiva ao atribuir forma, sentido e conteúdo às suas atividades ao ser constituído por outro(s) ao mesmo tempo em que constitui outro(s). É pela língua-discurso que se manifesta a experiência humana com e nas atividades de trabalho, questão a ser abordada na seção seguinte.

\section{O homem na cultura de seu campo de conhecimento: a experiência humana nas atividades de trabalho/de linguagem}

A aproximação que este estudo apresenta entre o campo ergológico e o campo enunciativo de linguagem relacionado à perspectiva de Émile Benveniste, ainda de forma embrionária, não é nova, pois esse encontro é registrado nas instigantes reflexões promovidas por Teixeira $(2009,2010,2012)$. É seguindo as "trilhas" da autora que se pode pensar nessa relação do homem com suas atividades de trabalho/linguagem. O depoimento de Teixeira e Cabral resume de forma bastante ilustrativa a riqueza possível do encontro ao qual se adere neste texto, aquele entre ergologia e enunciação:

estarmos hoje em contato com saberes interessados em pensar o que acontece na atividade de trabalho é resultado do exercício de colocar a linguística em diálogos que transcendam o que se tem considerado como seu escopo disciplinar. (TEIXEIRA; CABRAL, 2009, p. 237)

Isso porque, como atestam os próprios autores, a Enunciação, em especial a Teoria da Enunciação de 
Émile Benveniste, presta-se de uma forma muito rica a esse contato. Afinal,

O envolvimento com uma linguística sensível à questão da subjetividade, aliada ao desejo de ultrapassar o isolamento disciplinar, foi o que determinou nosso encontro com os estudos ergológicos sobre a atividade de trabalho.

Isso implica movimentar-se na direção daquilo que a linguística deixou por muito tempo como um "resto" impossível de ser integrado a seu objeto para não corromper um ideal de ciência, pautado pelo rigor, pela universalidade, pela lei geral, pelo repetível: o investimento subjetivo na linguagem [...]. (TEIXEIRA; CABRAL, 2009, p. 237)

O desenvolvimento das pesquisas de abordagem ergológica ${ }^{1}$, que mobilizam profissionais e trabalhadores na investigação do universo do trabalho, tendo o filósofo Yves Schwartz como principal representante, remete à prática de estudos linguísticos desenvolvidos por Émile Benveniste, o qual mantinha permanente diálogo com as áreas da psicologia, da filosofia e da antropologia. Entre os movimentos em comum dos pesquisadores da enunciação e da ergologia é possível identificar, essencialmente, o interesse em associar homem, linguagem e cultura aos seus respectivos objetos de estudo (língua/linguagem, no campo da linguística, e trabalho, na abordagem ergológica). Em outras palavras, ambos adotam uma perspectiva antropológica na investigação de seus objetos, o que representa examinar a dimensão humana da línguadiscurso e do trabalho.

Não há, a nosso ver, perspectiva linguística mais adequada para um contato com esse campo do que a Teoria da Enunciação Benvenistiana, que tem por princípio fundamental a intersubjetividade, sem a qual não há subjetividade e, portanto, sequer há linguagem. Por isso, prevê o linguista:

Muitas noções na linguística, e talvez mesmo na psicologia, aparecerão sob uma luz diferente se as restabelecermos no quadro do discurso, que é a língua enquanto assumida pelo homem que fala, e sob a condição de intersubjetividade, única que torna possível a comunicação linguística. (BENVENISTE, 1995, p. 293)

Considerando o objeto deste estudo - a leitura de texto de opinião de um profissional que se situa, no

\footnotetext{
1 A ergologia alia em seus princípios a história do conceito de atividade presente nas pesquisas em ergonomia à herança da filosofia da vida de Georges Canguilhem. São referências históricas da constituição do conceito de atividade estudos de Marx, Hegel e Kant. A atividade dos trabalhadores de indústrias e dos setores de serviços e saúde tem sido o principal objeto de estudo dos pesquisadores (cf. SCHWARTZ, 2006).
}

discurso sobre sua profissão, com formulações "Eu sou X", "A profissão X é Y", ou o "O profissional X atua de modo Y", para mostrar, de um lado, sua relação com "uma nomenclatura de profissões mais ou menos oficial e estandardizada" (TEIXEIRA; CABRAL, 2009, p. 242), de outro, para se declarar singularmente como profissional de tal campo como distinto do de outro -, este item busca estabelecer um diálogo entre os saberes da perspectiva enunciativa de linguagem e os da ergologia para, no próximo, propor a análise do modo como um profissional do campo de saúde situa-se no discurso e implanta o outro diante de si.

Ao se colocar em diálogo a reflexão de Schwartz (2010, p. 45) de que "trabalhar é sempre gerir debates de normas articuladas sobre um mundo de valores" com a noção benvenistiana de cultura como o que dá à vida e à atividade humanas forma, sentido e conteúdo por meio de uma "multidão de noções e de prescrições, e também interdições específicas" (BENVENISTE, 1995, p. 31-32), é possível tratar o artigo de opinião sobre uma profissão como um debate de normas e noções pelas quais o locutor se declara como "Sou X..." em uma relação intersubjetiva própria da estrutura de alocução "eu escrevo para um tu", ao mesmo tempo que efetua a operação de referência, já que "eu" escreve para "tu" sobre "ele" (a profissão). Nesse caso, a profissão comparece como uma ausência re-presentada no campo da presença (DUFOUR, 2000) - a referência do discurso (o tema) - e uma ausência irrepresentável, na qual se situam os valores culturais impressos nas atividades de trabalho que produzem sentido como um efeito da ação de uma forma sobre outras no fio do discurso.

De fato, Benveniste (1995, p. 30), ao situar seu estudo no domínio do sentido, não deixa de levar em conta que a linguagem comporta uma estrutura material, possível de ser descrita, e outra imaterial, possível de ser evocada, como se vê em suas palavras:

a linguagem é um sistema simbólico especial, organizado em dois planos. De um lado é um fato físico: utiliza a mediação do aparelho vocal para produzir-se, do aparelho auditivo para ser percebida. Sob esse aspecto material presta-se à observação, à descrição e ao registro. De outro lado, é uma estrutura imaterial, comunicação de significados, substituindo os acontecimentos ou as experiências pela sua "evocação".

Por isso, o autor defende que a linguagem está impregnada no homem "sempre em relação ao que se tem chamado as realidades que são realidades definidas como elementos da cultura, necessariamente" (BENVENISTE, 1989, p. 24). E complementa: 
damos sentido a certos gestos, não damos nenhum sentido a outros, no interior de nossa cultura. É assim por quê? [...]. A hierarquia, a ação recíproca destes valores, e consequentemente os modelos que são propostos, os objetos desejados, tudo isso se desloca no interior de nossa cultura. (BENVENISTE, 1989, p. 25-26)

Essa discussão remete à reflexão de Schwartz (2010) sobre haver normas antecedentes no fazer das atividades de trabalho, que se revelam no dizer dos envolvidos nessas atividades, remetendo à experiência humana que se instaura nas práticas sociais de trabalho e de emprego da língua, com suas tendências de renormatização e particularização. E aqui ganha relevo novamente a formulação benvenistiana de "variação da referência na estabilidade da significação" (BENVENISTE, 1989, p.100), visto que, em uma perspectiva enunciativa, destaca-se o fato de que é no domínio da língua em ação que o discurso engendrado pelo locutor mostra a função mediadora da linguagem com o mundo, já que a relação homem-homem é atravessada pela dimensão cultural, constitutiva dessa relação intersubjetiva. Nesse sentido, o sistema de valores culturais é constitutivo do homem em seu exercício de linguagem.

Há, nessas relações de mutualidade "eu-outro; indivíduo-sociedade", uma semântica que atravessa a linguagem e carrega a maneira pela qual os elementos são valorizados. Essa capacidade simbólica está na base das funções conceptuais, de modo que enunciar é simbolizar a relação com o mundo via língua para o outro. Nesse ato, que se pode chamar de "simbolização", cada locutor, ao se propor como sujeito, implica um outro inscrito na cultura, pois é "dentro da, e pela, língua que indivíduo e sociedade se determinam mutuamente" (BENVENISTE, 1995, p. 27). Por isso, cada nova situação de apropriação da língua requer de cada locutor diferentes relações de integração da língua à cultura, em que o outro tem papel fundamental, já que "a língua carrega consigo uma série de dados herdados", herança que passa a ser do locutor no encontro com o outro por meio de enunciações. Isso porque "não há um aparelho de expressão tal que se possa imaginar que um ser humano seja capaz de inventá-lo sozinho" (BENVENISTE, 1989, p. 24).

Novamente as palavras de Benveniste parecem encontrar-se com as de Schwartz (2006), que compreende a perspectiva ergológica como constituída pelas peculiaridades das "construções linguageiras", que singularizam as relações de trabalho, ao mesmo tempo que se constituem como recursos linguísticos eficazes no cumprimento das atividades. Assim, nessa concepção, tratar da linguagem é seguir além da expectativa de adequação à formalidade e ao saber técnico. Ainda que a "linguagem codificada" (do engenheiro, do técnico etc.) não possa ser desprezada, ela não normatiza sozinha a complexidade das trocas necessárias para o cumprimento de tarefas.

A atenção da ergologia à linguagem do cotidiano do trabalho faz o pesquisador observar as duas dimensões que a constituem: a da linguagem na atividade (da experiência de trabalho) e a da linguagem técnica, dos conceitos e saberes. Observa-se, portanto, que a inovação da abordagem ergológica está em seu propósito de pensar sobre um homem que se constitui como sujeito pela linguagem em seu trabalho. Como diz Schwartz (2000, p. 6)

o próprio fato de poder reconhecer, de poder identificar sua expressão linguageira na atividade como uma espécie de criação e não como uma linguagem empobrecida é uma maneira talvez bastante extraordinária de reconsiderar sua própria relação com o trabalho.

Com o olhar para a atividade linguageira, a "experiência" coloca-se como outro importante conceito na investigação da relação linguagem e trabalho. Compreende-se, pois, que tratar da "experiência" implica refletir sobre a intersubjetividade, sobre o que é esperado do outro, sobre a não simplificação do outro ao "trabalho prescrito", já que a subjetividade se marca pela linguagem no "trabalho real", no "uso de si". ${ }^{2}$ Ou seja, observa-se que, nessa perspectiva, não há espaço para uma visão mecanicista de trabalho, já que toda atividade é uma ressingularização, ou uma renormalização parcial em torno de si.

Nesse sentido, existe a necessidade de reflexão sobre a atividade, para a qual a formulação de conceitos se faz necessária. Conforme destaca Schwartz, "precisase de conceitos para melhor compreender sua própria experiência de trabalho, senão ela não se liberta de certas limitações" (2000, p. 8). Assim, o filósofo sintetiza as duas dimensões da relação trabalho e linguagem segundo a perspectiva da ergologia:

- a dimensão da linguagem comum, no ardor do trabalho, na trama da atividade, que não se caracteriza como uma linguagem empobrecida;

- mas também a dimensão voltada para o conceito, a linguagem enquanto lugar no qual se fabricam conceitos; estes têm uma dimensão muito mais distanciada em relação à história e à atividade, mas passar pela experiência desses conceitos é um elemento de melhor reflexão sobre sua própria atividade. (SCHWARTZ, 2000, p.9)

\footnotetext{
2 Conforme Schwartz (2006, p. 460), a expressão “uso de si”, elaborada em 1987, transmite a ideia de que, mesmo numa situação de maior constrangimento, como no trabalho em linhas de montagem, existe atividade, transgressão, "renormatização" das normas, o que afasta da ideia da possibilidade de ação mecânica: "o que nos conduz à ideia de uso de si, porque, mesmo nas linhas de montagem, encontramos uso de si - seja 'por si mesmo', seja 'pelos outros'. Podemos então falar que, no trabalho, o uso de si envolve o 'uso de si pelos outros' e o 'uso de si por si mesmo".
} 
A reflexão apresentada encaminha que se formule a seguinte indagação: quais são os caracteres específicos que fazem com que esse encontro - trabalho e linguagem - seja bem-sucedido? A ergologia, como se situa acima, engloba estudos que dizem respeito à atividade do trabalho. A perspectiva desse campo que aqui se traz "considera que não se pode pensar o exercício profissional sem levar em conta que ele implica o trabalhador, suas escolhas e seus dramas interiores" (TEIXEIRA; CABRAL, 2010, p. 13). Ou seja

a ergologia interessa-se pelo trabalho como atividade efetivamente realizada por sujeitos, entendendo o termo "atividade" como uma dialética entre duas dimensões da atividade humana que estão ligadas no trabalho: o dizer e o fazer, isto é, entre a prescrição e o que efetivamente acontece. A perspectiva ergológica ensina que a atividade de trabalho é social, coletiva, normalizada, mas, ao mesmo tempo, engaja experiências subjetivas, que tendem a redefinir permanentemente os procedimentos. É o lugar de um jogo de reciprocidades entre o geral e o singular. (TEIXEIRA; CABRAL, 2009, p. 237)

Se, para Benveniste (1989, p. 222), "bem antes de servir para comunicar, a linguagem serve para viver" e na "falta de linguagem não haveria nem possibilidade de sociedade, nem possibilidade de humanidade", vê-se, como sintetiza Teixeira (2012, p. 43), que "o pensamento de Benveniste ultrapassa os limites da linguística para ligar-se a uma teoria geral da linguagem". Ademais uma teoria geral da linguagem é deveras produtiva para os estudos do trabalho, o que faz da relação entre os campos de enunciação e de ergologia constituir-se em um dos projetos que poderá contribuir para um programa teórico sobre uma ciência geral do homem.

Concebendo a perspectiva ergológica como vinculada à "indissociabilidade entre linguagem e trabalho", Schwartz $(2000,2006)$ diz não ser possível pôr tudo em palavras: "se reduzirmos a experiência àquilo que é da ordem do espontaneamente posto em palavras, em raciocínios claros para todo mundo, acredito que vamos deixar de lado uma parte enorme do que são saberes e competências na experiência" (SCHWARTZ, 2010, p. 41). É nesse ponto que se compreende como necessário atentar para o conceito de experiência da ergologia, contrapondo-o ao conceito de experiência possível de se estabelecer a partir do ponto de vista enunciativo, para o qual a experiência não se constitui fora da linguagem.

O debate proposto pelo filósofo Agamben (2012), a partir de uma concepção enunciativa de linguagem, permite situar a experiência na linguagem na cisão natureza/cultura, já que toda existência se dá na cultura, constitutiva e constituinte na e pela linguagem, corroborando a tese benvenistiana "de que o homem não nasce na natureza, mas na cultura" (BENVENISTE, 1989, p. 23).

Com relação à experiência, Schwartz (2010, p. 44) considera importante distinguir a experiência do trabalho e o trabalho como experiência. $\mathrm{O}$ autor pontua que há, de um lado, um saber formal (normas protocolares) que antecipa a experiência e, de outro, há as diferentes situações de trabalho que permitem a renormatização de conceitos. É nesse sentido que Teixeira (2012, p.41) observa que

operar com atividade humana, na perspectiva ergológica, coloca, então o fazer científico diante de uma dupla racionalidade: a) aquela orientada pelos saberes abstratos (em desaderência); b) aquela orientada pela atividade (em aderência local).

Isso é particularmente significativo se se pensa que, como ressalta Schwartz, as palavras não dizem tudo, não conseguem fazê-lo. "De fato", concordam Teixeira e Cabral (2009, p. 240), “as palavras não dão conta, elas não são transparentes, elas sofrem 'desvios' de toda ordem no trajeto até aqueles a quem se dirigem". Como afirmam esses autores,

\begin{abstract}
a nosso ver, os estudos enunciativos têm duas contribuições a dar aos outros campos, a primeira, de caráter mais amplo, no âmbito teórico, é uma concepção de linguagem; a outra, mais específica, no âmbito da prática, relaciona-se ao fornecimento de ferramentas para a análise da materialidade linguística propriamente dita. (TEIXEIRA; CABRAL, 2009, p. 237)
\end{abstract}

As atividades de trabalho com suas tensões entre normas antecedentes e renormatizações são lugares de instauração sempre renovados do homem na cultura, e consequentemente, lugares onde os discursos, produtos da enunciação, deixam os vestígios do que é de ordem social e o de que é de ordem singular, já que, para simbolizar e produzir sentidos às atividades de trabalho, $\mathrm{o}$ homem produz relações de interpretância. Nesse jogo, faz renascer a sua experiência do acontecimento, ou seja, a sua experiência na atividade de trabalho, representando-a para si e recriando-a para o outro via língua-discurso.

Considerando com Benveniste (1989, p.27) o fato de que "não produzimos a língua fora de certos quadros, de certos esquemas" e deslocando para o contexto deste escrito, em que se defende a concepção de que cada língua, cada cultura e cada campo de saber empregam um aparato específico de símbolos pelo qual cada sociedade se identifica, a seção seguinte busca, por meio de uma breve análise de um artigo de opinião de um autor da área médica, apreender os quadros e os esquemas ligados a essa profissão e à singularidade do locutor com o seu fazer para mostrar, por seus dizeres, a inscrição da experiência 
humana nas atividades de trabalho simbolizadas na linguagem.

\section{3 o trinômio homem-cultura-língua integrados no discurso do campo da saúde}

Para a análise, selecionou-se um artigo de opinião que traz a posição de seu autor - um médico - acerca de seu fazer. O objetivo, como mencionado, é responder à questão: "como um autor da área de ciências da saúde enuncia a sua posição de locutor para implantar o outro diante de si em um artigo de opinião?”.

Embora não haja um padrão de artigo jornalístico, pode-se dizer que, de modo geral, sua estrutura exige um tema relevante apresentado em linguagem acessível para os leitores não especializados do veículo midiático em que é publicado (seja on-line, seja impresso) e que nele se dê maior ênfase à opinião do que às demonstrações.
Entretanto, para emitir uma opinião, é preciso informação para embasar a argumentação; para dar uma informação, é preciso partir de um ponto de vista, ou seja, de uma opinião ligada à assinatura do autor, visto que o leitor a procura justamente para saber como o articulista pensa e reage diante dos acontecimentos atuais. Como opinião e informação são inseparáveis (CHAPARRO, 2007), há no artigo jornalístico esses dois elementos essenciais: opinião e informação relacionada à leitura da atualidade. Esses dois elementos permitem ao articulista (jornalista ou especialista de um campo de conhecimento) sustentar seu ponto de vista a partir de referências atualizadas nos discursos de outros locutores, discursos esses que circulam na sociedade.

Para análise que ora se propõe desenvolver, selecionou-se o texto "Me fale o que você está sentindo, doutor!"”, do médico oncologista Stephen Stefani, publicado em veículo de mídia impressa e digital no Dia do Médico (18 de outubro).

\section{Zero Hora, 18 de outubro de 2013 \\ ME FALE O QUE VOCÊ ESTÁ SENTINDO, DOUTOR! STEPHEN STEFANI*}

Médicos devem ser objetivos, racionais, capazes de ouvir e captar pontos relevantes para decifrar diagnósticos, e talentosos em comunicação, com empatia e carinho para contribuir para busca de soluções. A expectativa de um profissional humano (convenhamos... é o mínimo) e bem treinado, entretanto, já não é o suficiente. Atualmente se espera, no mínimo, uma pessoa que também seja disponível, com responsabilidade social e orçamentária.

A dicotomia reducionista de que o médico ou é um especialista atualizado e afastado das dificuldades do país, ou é um generalista sensível e engajado nos problemas sociais é de uma simplicidade grosseira e cria personagens para uso político e partidário. A mão no ombro é, realmente, muitas vezes (ou até sempre) fundamental, mas não substitui as outras necessidades. Uma coisa não exclui a outra. O médico versão 2.0 precisa estar conectado com o paciente e com o mundo.

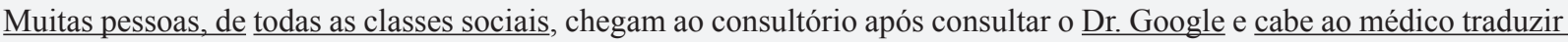
o que tem sentido naquela infinidade de informações digitais pouco críticas.

Agilidade na comunicação é outra prerrogativa fundamental. Telefones celulares, e-mails e redes sociais passaram a ser valiosos nesse sentido. Uma resposta rápida e eficiente pode salvar vidas, em uma guerra que não tem trégua.

No seu livro What Doctors Feel (traduzindo para algo como “O que o médico sente”), Dra. Danielle Ofri dissecou respostas emotivas ocultas dos doutores e como isso influencia os pacientes. Esse estresse da vida com jaleco - burocracias, estudos por horas, sobrecarga em plantões e momento de enfrentamento de mortes e tristezas - gera desdobramentos pessoais, familiares e profissionais para o médico. As angústias de compartilhar as dificuldade imensas do sistema de saúde criam, muitas vezes, profissionais que adotam mecanismos de defesa rústicos e ineficientes e acabam se afastando do objetivo principal que é entender o paciente e tentar ajudar com todas as ferramentas disponíveis.

Um olhar para esse lado emocional da medicina - incluindo medo, ansiedade, determinação, alegria - é fundamental. Todos esses sentimentos e a resposta emocional do profissional da saúde aos dramas de vida e morte têm profundo impacto no atendimento aos doentes. Pouco se debate sobre qual o sentimento desse operador de um sistema pesado e insuficiente. Pode funcionar melhor se houver alegria e orgulho no que se faz. É o único combustível que move o sistema, tão cheio de falhas.

Neste dia do médico, se algum profissional teve o privilégio de entrar na sua história, mande um e-mail, torpedo, ou uma ligação mencionando isso. Renovando lembranças de que se pode ajudar alguém é que se resgata o melhor que um médico pode ter e, de alguma forma, se consegue o melhor para os pacientes.

* Médico oncologista.

\footnotetext{
3 Os sublinhados no texto funcionam como elementos de destaque para auxiliar na compreensão da análise a ser realizada neste item.
} 
O autor, ao se apropriar da língua e se declarar como locutor, segue as linhas que caracterizam a estrutura de um artigo de opinião, ou seja, um texto argumentativo cujo ponto central, a opinião, está embasada em sua experiência profissional e nas significações estáveis sobre o fazer relacionado a essa experiência. Cabe lembrar que foi publicado no Dia do Médico e tem nas entrelinhas uma resposta às questões do Programa Mais Médicos ${ }^{4}$, o que demonstra a atualidade do dizer.

Destaca-se no texto a função enunciativa de intimação na abertura e no fechamento. Conforme Benveniste (1989, p. 86), essa função implica uma relação viva e imediata com o outro e, por isso, é marcada por ordens e apelos, que se caracterizam pelo uso de categorias linguísticas como imperativos e auxiliar modal "deve". O locutor apropria-se da forma modal "deve" para mostrar um saber sobre sua profissão e impor ao seu parceiro de atividade a adoção de condutas racionais e afetivas em suas atividades de trabalho. Essa função inicia o texto e retorna no fechamento, por meio de expressões com a marca pronominal de interlocução como "sua história" e por formas imperativas como "mande um e-mail, um torpedo, uma ligação". Desse modo, o locutor implanta no discurso outro tipo de alocutário além de seu parceiro médico, agora o paciente; esse diálogo, no final, revela um pedido para que, por meio do uso daquela mesma tecnologia que gera o estresse ("e-mail, torpedo, ou uma ligação"), haja reconhecimento de seu trabalho por parte desse "tu". Por meio dessa análise, observa-se que a referência à pessoa-não subjetiva ("tu") alterna-se no texto, remetendo a dois distintos alocutários (médicos e pacientes). No entanto, o modo como o locutor se constitui como "eu" para implantar esses distintos alocutários aponta a sua singularidade no emprego da língua, pois a repetição da função de intimação atesta seu lugar de saber sobre a postura e atuação do profissional médico nas atividades de trabalho e seu modo impositivo de implantar o outro diante de si.

Verifica-se, no primeiro parágrafo, um interessante uso de "nós" entre parênteses, para o locutor se situar na enunciação com um alocutário genérico (leitor geral), compartilhando a posição de necessidade de um profissional médico humano. Com esse uso, mostra que, intersubjetivamente, está em relação com discursos que tematizam a "desumanização dos profissionais da saúde". Nesse caso, o locutor declara-se como "eu" juntamente

\footnotetext{
4 Tal Programa é de autoria do governo federal e tem por objetivo levar atendimento médico a regiões remotas do país. No momento da produção do artigo, a ação do governo gerava grande controvérsia por trazer médicos de outros países sem que fosse feito, pelos Conselhos Regionais de Medicina, a validação dos diplomas desses médicos estrangeiros, o que é exigido pela legislação brasileira. Os médicos foram especialmente contrários ao Programa, alegando que há mais problemas estruturais para o atendimento nesses locais do que apenas a ausência de médicos.
}

com um "tu" para compartilhar significações sociais estáveis acerca das condutas desumanas de alguns profissionais de sua atividade de trabalho, das quais se distancia para se assumir como um profissional humano. Nesse mesmo parágrafo, merece destaque também o uso da expressão "se espera". Isso é significativo por ser marca linguística de textos da área da saúde, em que a busca de um efeito de impessoalidade é preponderante. Tal opção se explica, na perspectiva ergológica, pela necessidade de seguir um protocolo. Da mesma forma que os médicos utilizam, com seus pacientes, determinados procedimentos técnicos, apropriados para cada situação, sua forma de expressão linguística também segue um padrão, consagrado na sua área de atuação. É próprio da cultura dos textos da área das ciências da saúde que eles sejam validados no meio científico não apenas pelo saber, mas por um modo específico de enunciar esse saber um modo que privilegia o efeito de impessoalidade. São os "rudimentos da cultura", alusão a Benveniste (1989, p. 23), impressos na língua-discurso dos profissionais da medicina.

No segundo parágrafo, as expressões "dicotomia reducionista" - caracterizada pela oposição entre "especialista atualizado e afastado das dificuldades do país" e "generalista sensível e engajado nos problemas sociais" - e "simplicidade grosseira" revelam-se como resposta a posições sociais favoráveis ao Programa Mais Médicos, considerado pelo locutor como vinculado a "uso político e partidário".

A seleção de "o médico versão 2.0", "conectado" e "Dr. Google" evidencia que o interlocutor constituído pelo locutor - ou seja, o "tu" que o "eu" implanta diante de si - é alguém cujo acesso à tecnologia permite ao articulista o emprego dessa terminologia. Significativo, também, nesse uso de "Dr. Google", juntamente com "muitas pessoas, de todas as classes sociais", é o modo como o médico constrói a imagem do paciente padrão: alguém que igualmente tem acesso à tecnologia.

Com "cabe ao médico traduzir o que tem sentido naquela infinidade de informações digitais pouco críticas", o locutor expressa sua visão acerca do papel do médico nesse contexto: a de intermediar a relação entre o seu conhecimento técnico e as informações, em sua opinião, postas indiscriminadamente em circulação na internet, a que têm acesso muitos pacientes.

"Agilidade na comunicação", "telefones celulares", "e-mails e redes sociais", "uma resposta rápida e eficiente" são elementos que remetem diretamente àquele que está no centro da argumentação do locutor: o profissional da saúde com o "estresse da vida com jaleco". Essa atividade de trabalho é descrita como "burocracias, estudos por horas, sobrecarga em plantões e momento de enfrentamento de mortes e tristezas". Essa caracterização 
do estado emocional, que, na opinião do autor, prevalece entre os profissionais da medicina, acaba funcionando, no conjunto do texto, como explicação para a escolha do título: "Me fale o que você está sentindo, doutor!". Esse dizer dialoga com o enunciado corriqueiro dito e ouvido em consultórios médicos, ou, conforme Schwartz (2010), uma construção linguageira, um recurso linguístico eficaz para o cumprimento das atividades profissionais, no caso, médicas.

Nos consultórios, o médico se dirige ao paciente, perguntando-lhe de seu estado, sobre o motivo que o levou à consulta. Essa pergunta, dirigida do médico ao paciente, portanto, diz respeito a aspectos físicos, ligados à sintomatologia. Já no título do texto se refere ao estado psicológico do médico, sendo dirigida ao médico por ele mesmo, numa posição que se amplia aos seus pares, mas, ao mesmo tempo, faz refletir sobre seu próprio fazer. Igualmente, mostra que o locutor espera que seu interlocutor - um "tu" ampliado, um público geral não médico, identificado com os seus pacientes - reflita sobre a falta de humanização da profissão de médico por parte da sociedade. Ou seja, culturalmente, o médico não é visto como um ser humano, mas como uma função. Por isso, o locutor-médico converte a língua em discurso para atualizar sentidos que falam de sua condição humana de ser como associada ao seu fazer (sua condição de profissional da saúde), remetendo ao que Schwartz relaciona com a experiência de trabalho, lugar onde se interligam as duas dimensões de atividade humana: o fazer e o dizer. $\mathrm{O}$ locutor, então, se marca pela pergunta, que, embora seja própria de seu campo de atuação, é próxima o suficiente da experiência do outro, sendo possível, dessa forma, instaurá-lo na interlocução.

A menção à necessidade de haver "alegria e orgulho no que se faz" também é interessante por argumentar com o interlocutor acerca do sentimento almejado pelos integrantes de sua classe de trabalho, os médicos, que ele vê como "operador[res] de um sistema pesado e insuficiente". Assim, o locutor manifesta, a partir do pedido para que seu interlocutor lance "um olhar para esse lado emocional", seu desejo de esse outro também fazer parte da construção desse sentimento de satisfação em relação à sua atividade.

Sabe-se que a profissão de médico é valorizada socialmente, o que se dá, em parte, em função do caráter técnico e do saber da profissão. Por causa disso, acaba ocorrendo um distanciamento na relação entre paciente e médico. O que o locutor procura nesse artigo, no entanto, é um outro olhar: o lado humano da medicina, geralmente pouco evidenciado. Por isso, busca a valorização, pois, de sua experiência de trabalho, que é o "ele", referência que se instaura na interlocução. A busca pelo reconhecimento de sua atividade é, ao final, reforçada pelo argumento de que o bem-estar do paciente depende do bem-estar do médico ("Renovando lembranças de que se pode ajudar alguém é que se resgata o melhor que um médico pode ter e, de alguma forma, se consegue o melhor para os pacientes").

O locutor, ao se declarar como médico, integra seu discurso em significações estáveis sobre a profissão sintagmatizando expressões, que fazem parte do modo como profissionais dessa atividade de trabalho interpretam sua atuação. Além disso, implanta o alocutário ora como um parceiro médico que tem necessidade de cumprir alguns deveres, ora como um alocutário-paciente que também atenderia as "queixas" do médico, ora como um alocutário-geral a quem se dirige para homenagear sua profissão. Nesse sentido, implanta o outro diante de si em uma função mediadora de homens que partilham valores culturais que se imprimem na língua e, consequentemente, nos discursos relacionados a essa atividade de trabalho. Ao mesmo tempo que apresenta significações estáveis, o discurso traz a singularidade do locutor na escolha da argumentação produzida e nos diferentes modos de implantar o outro diante de si.

\section{Palavras finais}

A reflexão apresentada neste texto integra uma concepção enunciativa de linguagem a uma concepção ergológica do homem nas atividades de trabalho. Por meio dessa articulação, procurou-se responder à seguinte questão: "como um autor da área de ciências da saúde enuncia a sua posição de locutor para implantar o outro diante de si em um artigo de opinião?". A resposta a essa questão foi produzida a partir da crença da linguagem como função mediadora "entre o homem e o homem, entre o homem e o mundo" (BENVENISTE, 1989, p.229), pois "somente o funcionamento semântico da língua permite a integração da sociedade e a adequação ao mundo [...]" (BENVENISTE, 1989, p.229). Essa integração à sociedade e adequação ao mundo envolve, nas práticas sociais e, consequentemente, nas atividades de trabalho, o jogo entre normatizações e renormatizações (SCHWARTZ, 2010), visto que o geral e o singular são constitutivos da experiência humana nas atividades de linguagem e de trabalho.

Por isso, torna-se importante o docente, nas situações de ensino-aprendizagem em Língua Portuguesa com alunos de diferentes campos de saber, realizar um trabalho de análise textual que possibilite aos discentes fundaremse nas enunciações de sua área de conhecimento para, por meio da linguagem, instaurarem-se em novas experiências humanas de sua cultura profissional para se constituírem em relação a outro(s) em sua futura atividade de trabalho. 


\section{Referências}

AGAMBEN, Giorgio. Infância e história: destruição da experiência e origem da história. Tradução de Henrique Burigo. Belo Horizonte: Editora UFMG, 2012.

BENVENISTE, Émile. Problemas de linguística geral II. Tradução Eduardo Guimarães et al. Campinas, SP: Pontes, 1989.

BENVENISTE, Émile. Problemas de linguística geral I. Tradução Maria da Glória Novak e Maria Luisa Neri. 4. ed. Campinas, SP: Pontes, 1995.

CHAPARRO, Manuel Carlos. Sotaques d'aquém e d'além mar: travessias para uma nova teoria de gêneros jornalísticos. São Paulo: Summus, 2008.

DUFOUR, Dany-Robert. Os mistérios da trindade. Tradução Dulce Duque Estrada. Rio de Janeiro: Companhia de Freud, 2000.

NAUJORKS, Jane da Costa. Leitura e enunciação: princípios para uma análise do sentido na linguagem. Porto Alegre: UFRGS, 2011. [Originalmente apresentada como tese de doutorado pela Universidade Federal do Rio Grande do Sul, 2011.]

SCHWARTZ, Yves. Trabalho, Educação e Saúde [on-line], v. 4, n. 2, p. 457-466, 2006. ISSN 1981-7746. Disponível em: $<$ http://dx.doi.org/10.1590/S1981-77462006000200015>. Acesso em: 10 nov. 2013.
SCHWARTZ, Yves. A linguagem no trabalho. Tradução Cecília Souza-e-Silva e Décio Rocha. Travail et ergologie: entretiens sur l'activité humains. Schwartz, Yves; Durrive, Louis (Org.). Toulouse: Octarès, 2000. Disponível em: $<\mathrm{http}$ :// sites.univ-provence.fr/ergolog/html/ergologia_franco-luzitana fichiers/schwartz_Trabalho.pdf>. Acesso em: 9 nov. 2013.

SCHWARTZ, Yves. A experiência é formadora. Tradução Daisy Moreira Cunha. Revista Educação e Realidade, v. 35, n. 1, p. 35-48, 2010

TEIXEIRA, Terezinha Marlene Lopes. Linguagem, singularidade e atividade de trabalho. Cadernos IHU Idéias (UNISINOS), v.132, p. 1-26, 2010.

TEIXEIRA, Terezinha Marlene Lopes. $\mathrm{O}$ ato enunciativo e a instauração da experiência de trabalho de profissionais de enfermagem. Moara, v. 38, p. 38-54, 2012.

TEIXEIRA, Terezinha Marlene Lopes; CABRAL, Éderson de Oliveira. Linguística da enunciação e ergologia: um diálogo possível. Educação Unisinos, v. 13, p. 236-245, 2009.

Recebido: 30 de novembro de 2013 Aprovado: 03 de março de 2014

Contato: carmem.luci@ufrgs.br liacremonese@gmail.com simonelimabar@gmail.com 